\title{
The Analytics of the Australian Private Health Insurance Rebate and the Medicare Levy Surcharge
}

\author{
Alex Robson, Henry Ergas and Francesco Paolucci ${ }^{1}$
}

\begin{abstract}
This paper presents an analytical framework for examining changes in the Private Health Insurance rebate (PHIR) and the Medicare Levy Surcharge (MLS), and uses it to establish three key propositions. First, increases in the MLS rate tend to reduce the elasticity of demand for private health insurance. Second, simultaneously increasing MLS rates and thresholds has a theoretically ambiguous effect on PHI take-up rates. Third, means testing the PHIR can never increase PHI take-up, and will reduce it in some circumstances. The paper concludes with a discussion of the possible consequences of recently proposed policy changes to private health insurance in Australia.
\end{abstract}

\section{Introduction}

The Australian public-private mix in healthcare financing and the regulatory framework in the private health insurance market shape private health insurance market outcomes and performance in the following ways. First, the public insurance program (i.e. Medicare) provides a floor under the entire health system in Australia, with changes in quality and waiting times in the public system continuing to influence demand for private health insurance (PHI). Second, the 'community rating' and 'open enrolment' regulations for private health insurance mean that providers are heavily restricted in the extent to which they can charge different prices for consumers with different risk classes, though some (potentially significant) risk selection occurs through the design of insurance products. Third, increases in PHI premiums are regulated, with annual increases above the CPI requiring approval by the Health Minister each year.

1 Alex Robson, Griffith University; arobson@deloitte.com.au; Henry Ergas, Deloitte Access Economics and the University of Wollongong; Francesco Paolucci, Australian National University. 
The impact of the Medicare system and other regulatory features (in particular, the community-rating regulations) on PHI demand can be seen in the steady decline in PHI membership numbers following the scheme's (re)introduction by the Hawke government in 1984. In the absence of other policy interventions in particular, the lifetime health cover, the premium rebate and the Medicare Levy Surcharge introduced in the period between 1997 and 2008 - it is likely that PHI members would have continued to decline. ${ }^{2}$

Over the past years, it has been argued that the private health insurance rebate is poorly targeted, and that the rebate disproportionately affects inframarginal consumers: those individuals and families who would take out private health insurance in any event, even in the absence of any rebate. In addition, policymakers have modified the premium rebate arrangements by introducing age-related adjustments. For example, in 2009 the Government proposed that for individuals on incomes between $\$ 75,000$ and $\$ 90,000$, the rebate would be 20 per cent for those aged less than 65 years old, increasing to 25 per cent for individuals between 65 and 70, and 30 per cent for individuals aged 70 years or older. A second emerging policy trend is the increase and indexation of the income thresholds for the Medicare Levy Surcharge (MLS) and the recently proposed changes in MLS rates. These two policy trends have been partly motivated by emerging fiscal constraints, but the way in which they interact and their broader consequences for future fiscal and health outcomes have not yet been completely explored or understood.

This paper presents an analytical framework for examining changes in the Private Health Insurance rebate and the Medicare Levy Surcharge, and uses it to establish several key propositions, including that means testing the PHIR can never increase PHI take-up, and will reduce it in some circumstances.

\section{The current regulatory and policy environment}

\section{The PHI Rebate and the Medicare Levy Surcharge}

The Private Health Insurance Incentives (PHII) Act 1998 introduced the 30 per cent private health insurance rebate. This rebate replaced the previous PHIIS

\footnotetext{
2 For a detailed overview and discussion of the regulatory framework in place in the PHI market in Australia, we refer to Paolucci et al., paper under review in this special issue.

Butler (2002), Frech et al. (2003), and Palangkaraya and Yong (2005) suggest that the sharp jump in PHI-enrolees, from about 30 per cent to 45 per cent of the Australian population occurred in July 2000, is attributable to the lifetime health cover policy, rather than the introduction of the PHI rebate and the Medicare Levy Surcharge.
} 
subsidy for low-income earners. From April 2005, the rebate for persons aged 65-69 years increased to 35 per cent and for persons aged 70 years and over it increased to 40 per cent.

The Medicare Levy Surcharge (MLS) of 1 per cent of income was introduced on 1 July 1997 and until recently applied to single individuals with taxable incomes in excess of $\$ 50,000$ and couples and families with combined taxable incomes in excess of $\$ 100,000$ who do not have 'sufficient' private hospital cover. This is defined as cover that is "provided by an insurance policy issued by a registered health insurer for some or all hospital treatment provided in an Australian hospital or day hospital facility'. These nominal thresholds were not indexed to inflation or to changes in average weekly earnings. The effect of nonindexation has been to reduce the thresholds by around 36.5 per cent in real terms since 1997, which is the change in the average level of prices (i.e. the CPI inflation rate) over that period. ${ }^{3}$

\section{The current policy environment and recent changes to the PHI Rebate and the MLS}

The Medicare Levy Surcharge is an additional tax on all taxable income, and is payable once taxable income reaches a certain threshold unless the individual purchases an adequate amount of private health insurance. It is important to realise that if the baseline against which we are assessing additional public expenditure is that all individuals would ordinarily pay the additional tax impost that is embodied in the MLS, then it may only be in an accounting sense that the MLS involves less 'public expenditure' than the PHI rebate.

In other words, to the extent that policy changes induce individuals not to pay the MLS, tax revenue is forgone as a result, and so the MLS can be regarded as a tax expenditure - all the more so as absent forcing people into PHI, the government could, as an alternative, simply charge them the MLS as a supplementary tax. Thus, assessed on an economic basis, it is not necessarily the case that replacing the rebate 'carrot' with the MLS 'stick' would tend to reduce public expenditure, broadly defined. Moreover, unless the MLS does not affect any individuals and is completely inframarginal (in which case, there is no need for it), the MLS is effectively a supplementary income tax (except that instead of paying the tax, the consumer buys PHI), with the same excess burden as a supplementary tax.

\footnotetext{
3 In addition to these policies, there are restrictions on the amount of excess that can accompany the insurance policy. PHI taken out after 24 May 2000 which has an 'annual front-end deductible' amount or excess of more than $\$ 500$ in the case of a policy covering only one person, or more than $\$ 1000$ for all other policies, does not provide private patient hospital cover for MLS purposes.
} 


\section{Recent changes to thresholds and rates}

Prior to 2008 the PHI rebate consisted of a single rate for individuals aged less than 65, and the MLS consisted of a single rate. The Australian Government has made several significant policy changes and announcements which have altered previous arrangements for the PHI rebate and the MLS. From 1 July 2008, the total taxable income for surcharge purposes above which the MLS of 1 per cent is payable was increased for single individuals, from $\$ 50000$ to $\$ 70000$, with the combined taxable income for surcharge purposes for couples and families increasing from $\$ 100000$ to $\$ 140000$. This change restored the thresholds roughly to their original 1 July 1997 levels in real terms and eliminated the MLS 'stick' ${ }^{4}$ for individuals and families whose income fell between the old and new thresholds.

The other significant policy change that occurred in 2008 was that the MLS thresholds will henceforth be indexed to changes in average weekly ordinarytime earnings (AWOTE). This change is not innocuous. Since AWOTE has tended to grow more rapidly than consumer price as real wages continue to grow, the MLS threshold will increase in real terms even if it is not adjusted by further legislative changes.

Predicting the overall effect that indexation will have on financial incentives to purchase PHI is complicated by two further considerations. First, real wage growth across different income levels is not uniform. Second, growth in real wages is not necessarily the same as growth in real taxable incomes, which is what an individual or family's possible MLS liability is based upon.

It is also important to note that even if current policy settings are left unchanged, growth in real premiums would alter the quantum of incremental financial incentives that individuals face for purchasing PHI. This occurs because the PHI rebate is an ad valorem or percentage subsidy, as opposed to a specific subsidy or a payment of a fixed dollar amount.

In its 2009 Budget the Government proposed additional changes to the MLS and the PHI rebate. These changes were part of the Fairer Private Health Insurance Incentives (FPHII) Bill 2009, which passed the House of Representatives but was ultimately defeated in the Senate on 9 September 2009.

The Government revived and reintroduced the proposed changes into the House of Representatives on 7 July 2011, in the form of the Fairer Private Health Insurance Incentives (FPHII) Bill 2011 and related bills. ${ }^{5}$ Instead of the

4 In the context of the MLS and the PHI rebate, this terminology is due to Palangkaraya and Yong (2005).

5 An earlier version of this paper discussed the FPHII 2009 proposed changes. One referee of this paper conjectured that 'The possibility [of means testing the PHI rebate] seems moot from a policy perspective, given that the proposal has been rejected by the Senate and it does not look likely that it will be revived.' This 
MLS applying at a single rate for individuals and couples and families regardless of income, as of 1 January 2012 the FPHII Bill proposed that there be three new 'Private Health Insurance Incentive Tiers'. Existing arrangements would remain unchanged for singles with income of less than $\$ 80,000$ per annum and families with incomes of less than $\$ 160,000$ per annum. The three proposed new tiers are as follows:

- Tier 1: Applies to singles with income of more than $\$ 80,000$ but less than $\$ 93$ 000 (more than $\$ 160000$ but less than $\$ 186000$ for families). The PHI rebate would be 20 per cent, increasing to 25 per cent at 65 years of age, and to 30 per cent at 70 years. The MLS would remain at 1 per cent.

- Tier 2: Applies to singles with income between \$93001 and \$124000 (\$186 001 and $\$ 248000$ for families). The PHI rebate will be 10 per cent, increasing to 15 per cent at 65 years of age, and to 20 per cent at 70 years. The MLS will be increased to 1.25 per cent.

- Tier 3: Applies to singles with income of more than $\$ 124000$ (more than $\$ 248$ 000 for families). No PHI rebate will be provided, regardless of age. The MLS will be increased to 1.5 per cent. ${ }^{6}$

\section{Financial incentives and behavioural responses: The basic economics of the MLS and the PHI rebate}

The previous section set out the current and proposed policies regarding the PHI rebate 'carrot' and the MLS 'stick'. To obtain a more complete picture of the effects of policy changes on PHI demand, we analyse incentives to purchase PHI, which depend on the individual's subjective valuation of the services provided by private health insurance.

In the discussion that follows, it is important to keep in mind that the demand for private health insurance in Australia is effectively a demand for insurance that is supplementary to the universal insurance that is provided by the Medicare system, rather than insurance for primary health care cover per se. In this setting the demand for PHI is driven by two factors:

1. A supplementary care component, affected by waiting times and the availability of treatments in private care that are rationed in public care. This

conjecture turned out to be premature and incorrect.

6 The proposed policy's major parameters are summarised on page 8 of the Explanatory Memorandum to the FPHII Bill. 
is a function of the gap in care level between the public and private sectors and of each individual's perception of his or her health risk; and

2. A supplementary amenity or service component, which depends on features such as private rooms, which depends mainly on income.

In what follows, we treat the insurance provided by Medicare as essentially a constant that is subtracted from the individual's loss in the event of ill-health. Assuming that the level of each of these in the public system can be treated as exogenous (or at least predetermined), recognising the supplementary character of PHI does not alter the substance of the analysis. On the other hand, if PHI coverage affects the level of these variables in the public system, then the analysis would need to endogenise public care demand and supply and take account of the feedback effects of the private system to the public system.

\section{Factors influencing individual demand for private health insurance}

In the economic literature the theory of the demand for insurance is a sub-field of the economic theory of choice under uncertainty. Typically (but not always) the expected utility hypothesis is used to study individual insurance choice behaviour under various conditions. In this framework, individuals (or families) face an uncertain set of possible future health risks, to which the individual assigns probabilities. Individuals have preferences over wealth levels or income and choose insurance, taking the price of coverage as given.

Purchasing health insurance changes the calculus of the risks that an individual faces. Insurance reduces the amount of income that the individual can use to purchase other goods and services, but also reduces the welfare loss that the individual faces in the event of ill-health. An individual's willingness to pay (WTP) for insurance depends on five broad sets of factors, each of which will enter the analysis that follows:

- Income

- Price

- Tastes

- Risk factors

- Characteristics of the insurance package offered.

The first two factors are self-explanatory, but the last three deserve further discussion. By tastes, we are referring primarily to an individual's attitudes towards risk. A zeromean risk is a risk which has positive variance but an expected value of zero. An individual is said to be risk averse if, starting from some initial income, they would prefer not to face a zero mean risk. 
By risk factors here we refer to the individual's subjective probability assessment of the health risks that they believe they will face, as well as the nature and size of those health risks. These in turn can depend on an individual's age, sex, ethnicity, and other characteristics. The characteristics of the insurance package here refer to the type of coverage that is offered, the excess attached to the policy, the exclusions, restrictions, and so on.

For the purposes of our analysis of the PHI rebate and the MLS, we are primarily interested in the influence of price and income on the demand for insurance. Becker and Ehrlich (1972) showed that if prices are actuarially fair, then the demand for net insurance coverage (payout less the premium) will be a downward-sloping function of price. However, Hoy and Robson (1981) showed that the demand for gross insurance coverage may, in principle, be upward sloping (referred to in economics as a Giffen good), although they ruled out this possibility on empirical grounds.

If insurers incur costs in addition to insurance payouts, then an additional amount known as a loading factor will be needed to cover those costs. Even in a perfectly competitive insurance market in which each firm earns normal economic profits, the presence of such a loading factor means that premiums will exceed those that are actuarially fair. Thus consumers will demand less than full insurance coverage, even if they are very risk averse. The extent of coverage (known as the coinsurance rate) is increasing with the individual's degree of risk aversion. For a sufficiently large loading factor, zero insurance demand may be individually optimal. However, an increase in the loading factor may increase or reduce the individually optimal coinsurance rate if the individual has decreasing absolute risk aversion.

The reason for this ambiguous result is as follows. As a matter of theory, precisely predicting the effects of changes in income on insurance demand is not straightforward, although the economic reasons for this are relatively straightforward to understand. Consider, for example, the effect of higher income on insurance demand in the situation where an individual faced a loss that is fixed in size and is not related to income. Higher income is generally associated with a lower degree of risk aversion towards absolute dollar losses (this is known in the literature as declining absolute risk aversion, or DARA). If the individual faces prices that are actuarially fair (that is, the price of purchasing a dollar of coverage is equal to the probability of the loss), then the consumer always fully insures no matter what their income level. Thus, if prices are actuarially fair, the income elasticity of demand for insurance is zero. ${ }^{7}$

7 A referee questioned the empirical relevance of our discussion of no or negative income effects. Our discussion is simply drawing on the classic proposition that in the presence of fair insurance, one completely 
On the other hand, if the consumer faces prices that are not actuarially fair (that is, price is greater than loss probability), then they will purchase less than full coverage, and an increase in income under DARA will make them less risk averse, which means that they will purchase less insurance. To understand this result, note that the act of not purchasing insurance is similar to the act of purchasing a risky asset for a typical investor. As an individual's degree of risk aversion falls, their demand for risk assets rises. Furthermore, as an individual's income rises, it is usually the case that their degree of risk aversion falls, given decreasing marginal utility of income. Thus, returning to the health insurance setting, the implication is that as an individual's income rises, their demand for the risky asset rises, and the demand for the asset that reduces risk - health insurance - falls. In other words, if individuals have declining absolute risk aversion, the demand for health insurance is an inferior good. Under these circumstances, the income elasticity of demand for insurance will be negative. ${ }^{8}$

\section{Lessons from standard consumer theory}

Figures 1 and 2 use a standard diagram from microeconomic analysis to examine the economic effect of the MLS on the consumer's budget set or consumption possibilities. In Figure 1 the consumer can consume PHI and a composite good, labelled 'all other goods'. In the absence of the MLS, the consumer's budget set is enveloped by the solid black budget line, which describes the consumer's consumption possibilities when all income is spent. This budget line is affected by the consumer's income (which determines the overall position of the budget line relative to the origin) and the prices of each good (which determine the slope of the line).

In Figure 1 the consumer faces no MLS and chooses an amount of insurance equal to PHI. ${ }^{9}$ But for a consumer with a given income and facing a given set of prices, the MLS creates a 'kink' in the budget line at the point defined by the 'adequate' amount of PHI (labelled 'Min PHI' in Figure 2). This happens for the following reasons. If the consumer purchases less PHI coverage than Min PHI, the MLS reduces their income by an amount equal to the MLS rate multiplied by their income. If, on the other hand, the consumer purchases PHI coverage

insures, regardless of one's income. So, rich and poor both completely insure, and the income elasticity of the demand for insurance is zero. Our point here is simply the sign of the income elasticity can in theory be positive, negative, or zero. We discuss empirical estimates of income elasticities below.

8 This was first proved by Mossin (1968). However, this result needs to be modified in the presence of demand-side moral hazard, which can return insurance to a normal good. The conclusion also fails to hold if losses are proportional to income.

9 Figure 1 has the consumer choosing, in the absence of the MLS, a PHI package that is less than the minimum needed to avoid the MLS. A referee commented that, in practice, such packages are unlikely to be available, and that the most likely choice in the absence of the MLS would simply be no insurance. This neglects the possibility that individuals in this situation may decide to self-insure, rather than purchase market insurance. Figure 1 allows for both possibilities. 
that is at least equal to Min PHI, then they do not have to pay the MLS and the budget line is unaffected. The open circle at the lower point in the 'kink' reflects the fact that when the consumer purchases PHI that is even slightly less than the Min PHI, they will be subject to the MLS. But as soon as the minimum amount is purchased, the entire MLS is avoided. Thus the consumer's budget line is continuous from the right at the kink, but is not continuous from the left.

Figure 1: The economics of the Medicare Levy Surcharge

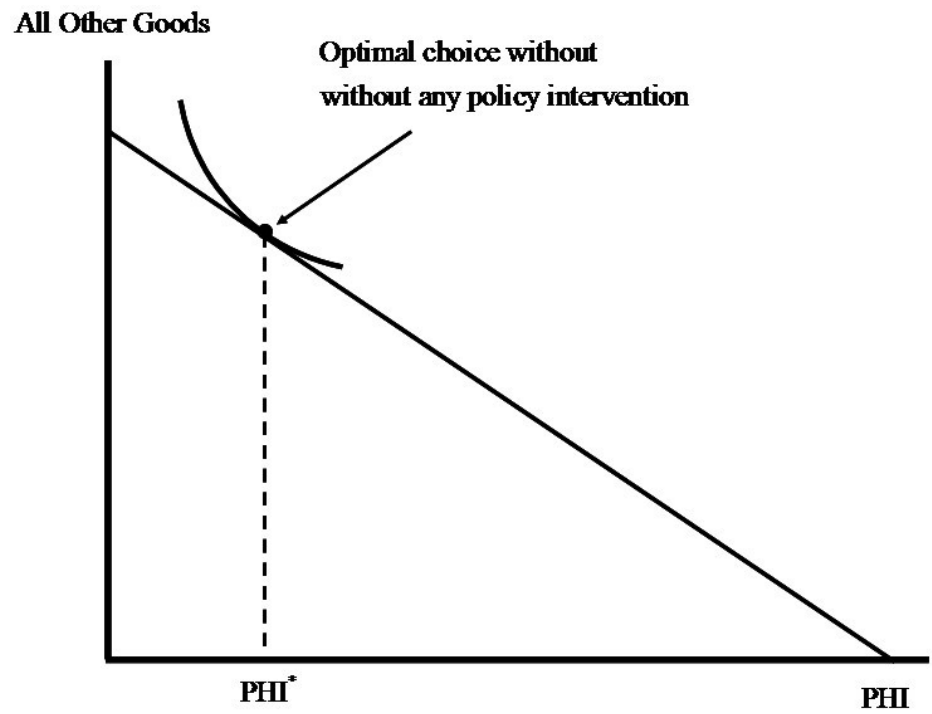

Figure 2: A PHI rebate which is sufficiently large to induce all consumers to purchase $\mathrm{PHI}$

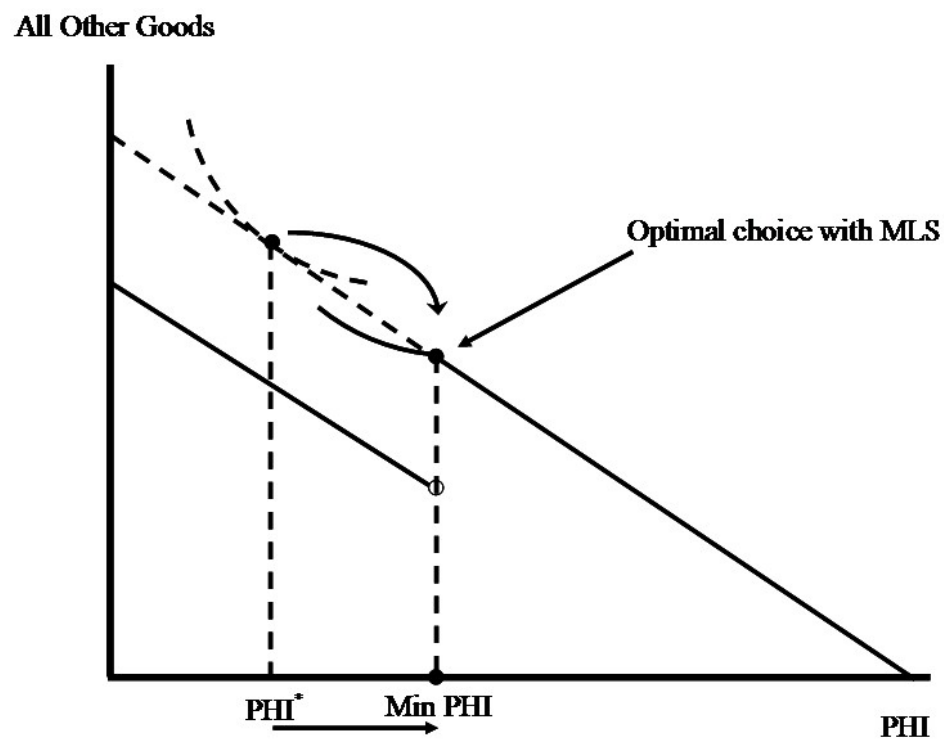


If the consumer ignores the intervention and pays the MLS, then less private health insurance is consumed than otherwise would be (assuming that PHI is a normal good), ${ }^{10}$ and the consumer is worse off than if they purchase the minimum package and avoid paying the MLS.

If, on the other hand, the consumer uses his or her resources optimally, then in Figure 2 the minimal PHI package will be chosen. In this case, even though the consumer avoids paying the MLS, the threat of imposition of the MLS still makes the consumer worse off, compared to the situation in which the MLS is not imposed.

The welfare loss of the MLS is the utility loss between the original and the new situation, and can be measured in income terms as the amount of goods given up in order to avoid paying the MLS. It is the 'distance' between the two indifference curves in Figure 2.

Note that the MLS consists of two policy levers, both of which affect the consumer's behaviour. The first policy tool — the actual surcharge itself varies in absolute dollar amounts for consumers of different income levels. That is, higher-income consumers face a greater absolute dollar penalty if they fail to purchase the minimal PHI package. The second policy lever is the minimum PHI package. This lever also influences the consumer's behaviour and in principle could also be used to influence PHI take-up. ${ }^{11}$

It is also important to note that the consumer's preferences and income may be such that he voluntarily chooses to purchase PHI even in the absence of the MLS - in which case the imposition of the MLS would have no effect. We label these types of consumers 'High PHI Valuation Consumers'.

Finally, suppose that the MLS is relatively low, or that the minimum PHI is relatively high compared to the consumer's choice in the absence of any package. The consumers may place such a low value on PHI (or the minimum package is defined to be very high relative to his initial choice) that they choose to pay the MLS rather than purchasing the minimum PHI package. But, as a consequence, because the consumer now has less income to spend, less PHI is also purchased

10 Butler (2002) estimates income elasticities of demand for private health insurance in Australia of 0.24 for hospital insurance, and 0.2 for ancillary insurance. For the purposes of this section, it is the sign rather than the size of the elasticity that is crucial.

11 Note also that the use of this approach for welfare analysis is only partially complete, because it ignores the economic distortions caused by the Medicare and public hospital system. If the benefits and costs to the individual of these additional interventions are taken into account, then the consumer's initial choice in the absence of the MLS in the diagram occurs in a second-best policy setting. In such situations, welfare analysis of additional distortions must be approached with a great deal of care. Indeed, in a second-best setting it is possible that the MLS could make consumers better off, once the effects of other policy interventions are taken into account. 
(assuming insurance is a normal good). The MLS has perverse effects here, because it reduces the demand for PHI rather than increasing it. ${ }^{12}$ We call these types of consumers 'MLS Payers'.

The above analysis suggests that there will be a threshold level of the MLS, beyond which the consumer would prefer to purchase the minimum PHI package than avoid purchasing it and paying the MLS. This threshold is the consumer's point of indifference between purchasing and not purchasing. Since consumer preferences vary, this threshold will vary among consumers according to their individual tastes.

\section{Implications of the MLS for the price elasticity of demand for private health insurance}

The design of the MLS has some interesting and important implications for consumer demand behaviour and government revenue when PHI premiums are fixed. But the preceding analysis also has potentially even more important implications for consumer demand and government revenue when PHI premiums change.

One of the most important implications of the MLS is the effect that it can have on the responsiveness of demand to premium changes for certain consumers. For consumers who purchase the minimum PHI package in order to avoid paying the MLS (whom we will henceforth call the 'MLS Avoiders'), an increase in PHI premiums may have no effect on their demand for private health insurance, even though such a price change ordinarily (that is, in the absence of the MLS) would have an effect. In other words, these MLS avoiders will likely have a price elasticity of demand of zero.

The reason for this can be seen in Figure 1: if the consumer is purchasing the minimum package in order to avoid paying the MLS, then that same 'MLS avoidance' strategy will still be optimal for them after a small increase in the premium (a tilting inwards of the budget line). The premium increase certainly makes the consumer worse off, but the utility loss that the individual experiences as a result of the premium increase is not sufficiently high to induce them to purchase less or no insurance and incur the MLS.

Thus, one of the effects of the MLS is to eliminate the consumer's price responsiveness. Note the important implication that if there is imperfect competition on the supply side (which is almost certainly true in Australia),

12 On the other hand, this particular policy configuration maximises government revenue, as the consumer actually pays the MLS rather than avoiding it. 
the reduction in the elasticity of demand brought about by the MLS will likely increase mark-ups, both reducing consumer welfare and increasing the additional total budgetary cost of the PHI rebate out when premiums rise. ${ }^{13}$

\section{The $\mathrm{PHI}$ rebate}

The PHI rebate is an ad valorem (percentage) subsidy on purchases of PHI. The effect of this subsidy is to tilt the consumer's budget line around the vertical axis to the right, so that for the same amount of income and any choice of other goods, the consumer can now afford to purchase more PHI. Assuming that $\mathrm{PHI}$ is a normal good (or, if it is inferior, that the (positive) substitution effect outweighs the negative income effect of the lower price), the demand for PHI increases in response to an increase in the PHI rebate.

In the presence of the PHI rebate the key points regarding the incentive effects of the MLS all still hold. In particular, introducing the PHI rebate does not change the possibility that there will be a group of consumers - MLS avoiders - who will have zero price elasticity of demand in the presence of the MLS.

The key lesson from this analysis is that an individual consumer's behavioural response to changes in the PHI rebate is straightforward to analyse, but predicting the response to changes in MLS rates and thresholds depends on two broad factors:

\section{- Income}

- Preferences or willingness to pay for insurance, which in turn depend on risk characteristics and the degree of risk aversion.

If these two factors were perfectly (either positively or negatively) correlated, then analysing and predicting the aggregate effects of policy changes would be relatively easy. One would only have to know a consumer's income to immediately have a reasonable idea of their willingness to pay for insurance, and it would then be relatively straightforward to predict the aggregate effect of policy changes such as changes to the MLS which, as the preceding analysis shows, are income-related. On the other hand, if we knew the position of the individual's indifference curve for a given income level, it would then be possible to use the analytical framework outlined in this section to predict the consumer's behavioural response to changes in the MLS, and knowledge of the individual's income would be sufficient.

13 Note that the increase in margins (i.e. the benefit of the reduced elasticity of demand) may not be captured by the PHI funds if the upstream suppliers (such as private hospitals and specialists) have market power. In that case, they may be the prime beneficiaries of the inelastic demand. 
However, for a variety of reasons, income and willingness to pay for private health insurance are not perfectly correlated. For example, individuals typically have different attitudes towards risk as measured by their degree of risk aversion, and thus within a given population of individuals, willingness to avoid risk varies not only as the same individual's income changes, but also across different individuals with the same income.

Thus, there are essentially two issues involved in the aggregate analysis of the effects of the MLS and the PHI rebate. The first is the impact of changes to the MLS and the PHI rebate on consumers considered by income level. The second is the impact by consumer level of risk; that is, as between low and high risks. If increasing the MLS increases the share of the PHI base that is high income, then (even with the rebate being income tested) the share of the rebate flowing to high-income groups is likely to rise. Moreover, assuming the supply side is imperfectly competitive, the reduction in demand elasticity brought about by the MLS will increase margins, and hence increase the dollar value of the rebate.

At the same time, it is likely that the marginal consumers who are forced into PHI by the increased MLS are low risk, which means both that there is a consumer welfare and associated efficiency loss (as those consumers value PHI at less than cost) and that the share of the rebate flowing to low risks rises. This shift in the risk composition of the PHI pool may have consequences for public outlays. If PHI and the consumption of health services are complements, or if the moral hazard problems associated with double coverage are material, then overall health costs may rise. This will also happen even if PHI and consumption of public services are substitutes, but high risks leave and low risks join the PHI pool.

To examine all of these effects, a simple analytical framework is needed to assess the possible aggregate effects of changes in MLS arrangements and the PHI rebate as incomes vary across the population. This is done in the next section.

\section{The interaction of the MLS and the PHI rebate as consumer incomes vary}

Because the incidence of the MLS depends on consumer incomes, it will affect different consumers differently. Moreover, the changes proposed in the FPHII (2011) Bill would also make the PHI rebate dependent on income. Understanding how the two policy tools can interact with each other across different income levels is crucial for understanding the possible aggregate effects of future changes to the MLS and the PHI rebate. 


\section{Analytical framework}

To understand this interaction across a population of different incomes, we use Figure 3 below, which plots income on the horizontal axis and willingness to pay for PHI, together with financial incentives, on the vertical axis. In the analysis that follows, we allow incomes to vary but assume that each consumer has an identical willingness to pay for PHI, which we also assume to be less that the price of the package. In other words, in the analysis that follows, we assume that without policy intervention, no consumer would purchase PHI.

In this environment, consider the effect of introducing a non-means tested PHI rebate. Since consumers are all assumed to have the same willingness to pay for PHI and since the rebate is not means tested, there are two possible outcomes: either all consumers now purchase PHI, or none will.

Figure 3 shows the situation where the rebate is sufficiently high to induce all consumers to purchase PHI - the difference between willingness to pay and the new subsidised price is positive. In this figure and the ones that follow, aggregate demand for (or take-up of) PHI is measured from right to left - it is the fraction of consumers whose net willingness to pay (inclusive of PHI rebate 'carrots' and MLS 'sticks') exceeds zero. The budgetary cost of the rebate scheme is the price of PHI multiplied by the subsidy rate, multiplied by the take-up rate and is given by the shaded area in Figure 3. MLS revenue is given by the tax rate, multiplied by the incomes of individuals who are above the MLS threshold but who do not purchase PHI.

Figure 3: The MLS when the PHI rebate is sufficiently large to induce all consumers to purchase PHI

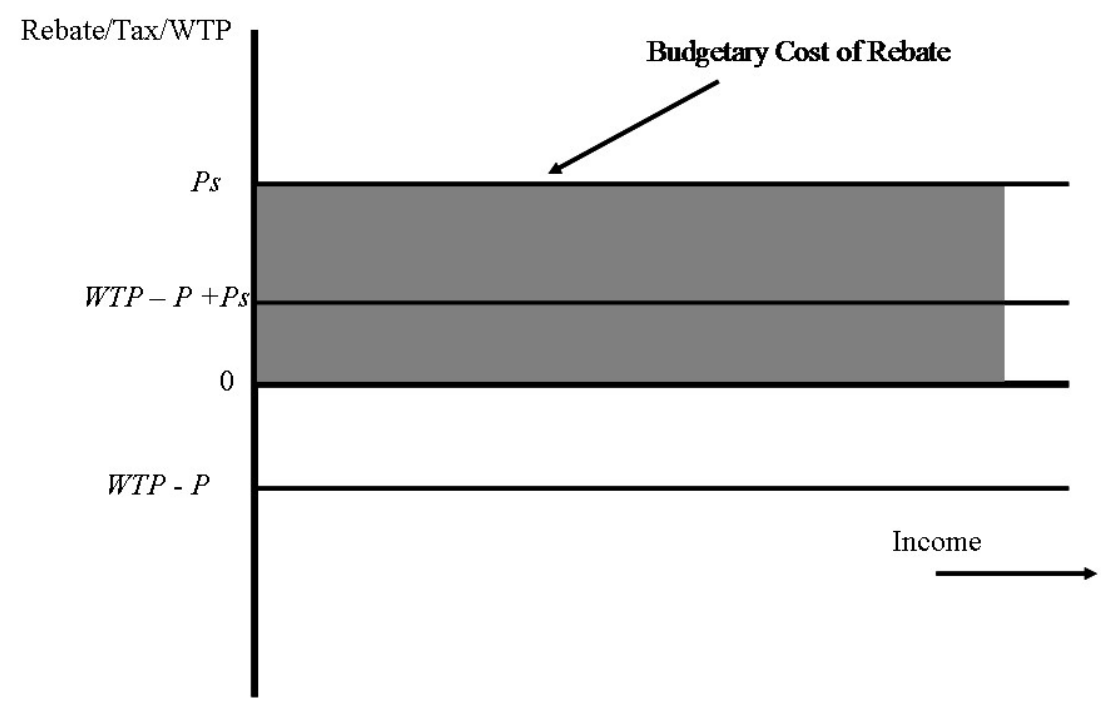


Figure 4 below shows a situation in which the MLS is introduced. The introduction of the MLS creates a kink in the net willingness-to-pay curve at the MLS threshold. For individuals on incomes exceeding this threshold, there is an additional tax levied on all income earned. The slope of the line is the MLS rate. In deciding whether to purchase PHI, the individual now assesses whether the willingness to pay, less the subsidised price, plus the MLS payment is greater than zero. With an MLS this sum is now a function of income, and is shown by the top line in the figure.

The PHI take-up rate is given by the fraction of individuals for which this kinked line is above the horizontal axis. In Figure 4, this is true for all income levels, and so there is 100 per cent take-up of PHI - and no individuals actually pay the MLS. The budgetary cost of the rebate is given by the shaded area.

\section{Figure 4: The MLS affects consumer behaviour but collects no revenue}

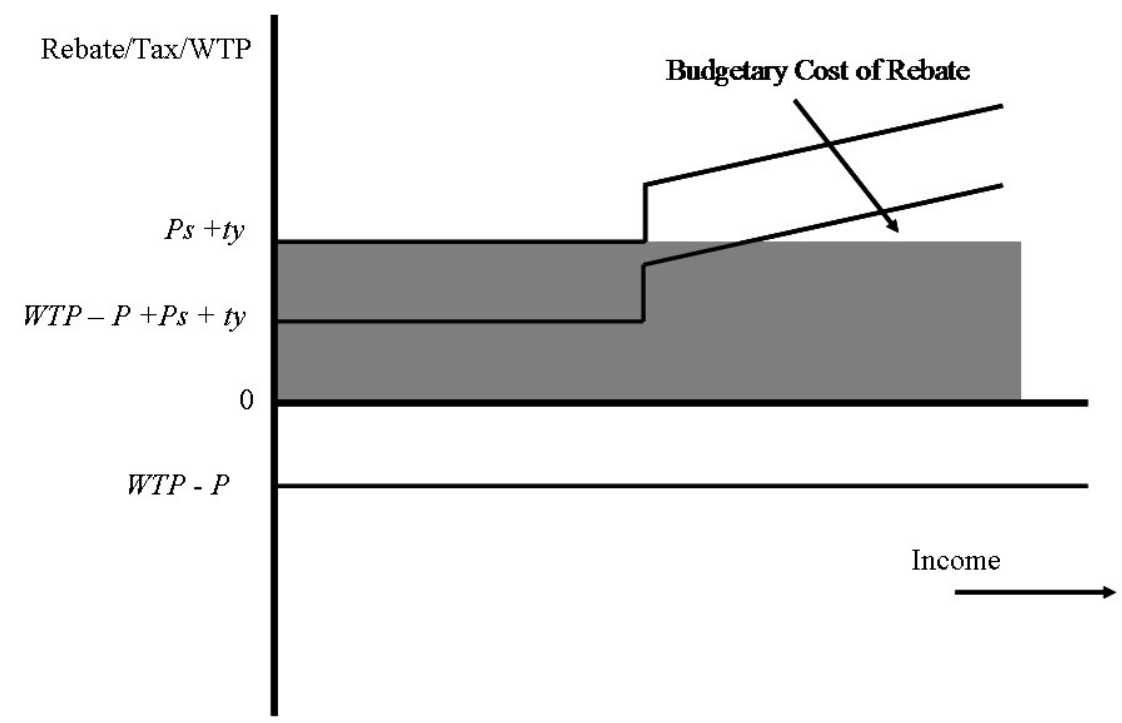

If the PHI rebate is low relative to willingness to pay, the MLS may play a role in inducing individuals to purchase PHI when they otherwise would not. In Figure 5, the MLS increases the cost of not purchasing PHI for those individuals above the threshold, which is again indicated here by $\mathcal{y}$. In this example, all individuals to the right of this cut-off point purchase PHI. However, since all individuals above the MLS threshold purchase PHI, there is no revenue from the $M L S$. Nevertheless, even though no individual pays the MLS, its presence still has an effect on individual incentives and behaviour. 
Figure 5: An increase in the MLS rate and threshold which increases $\mathrm{PHI}$ take-up

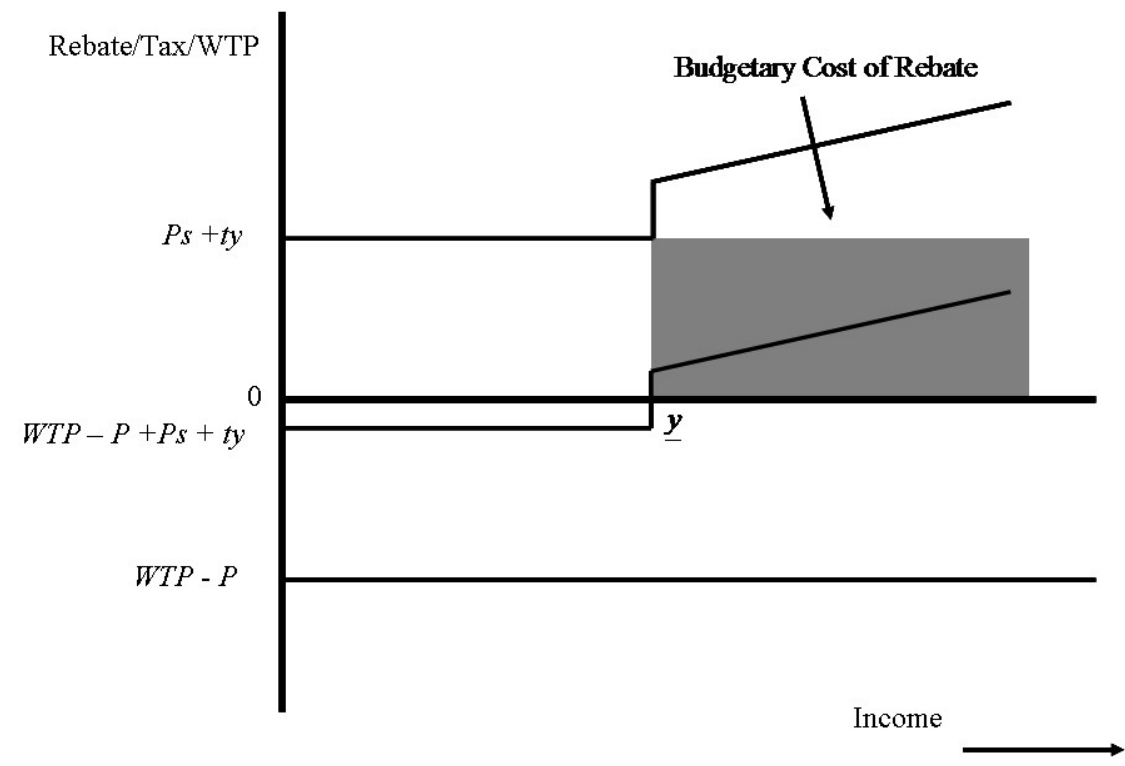

\section{Changes in Policy Parameters}

The above framework can be used to qualitatively analyse the effects of changes in the main policy parameters (the PHI rebate rate, the MLS threshold, and the MLS rate) on PHI demand, tax revenue, and the budgetary cost of the rebate.

\section{A combined increase in the MLS rate and the MLS threshold}

Consider, for example, the effects on PHI demand of a combined increase in the MLS threshold and MLS rate. The overall effects are ambiguous, and the reasons can be understood by examining Figure 6: on the one hand, an increase in the MLS threshold may either reduce PHI take-up or have no effect. On the other hand, an increase in the MLS rate (an increase in the slope of the net WTP line) unambiguously increases take-up. Combining the two policies yields an ambiguous outcome.

The case where the latter effect more than offsets the former (so that PHI demand increases) is shown below. The new higher MLS rate affects individuals who originally do not wish to purchase PHI. The change in the threshold in Figure 6 is drawn so that it has no effect on its own. In this case, it is the change in the MLS rate that does all of the work by increasing the financial incentive to take out PHI for the group of consumers with incomes between $y_{1}^{*}$ and $y_{2}^{*}$. The 
government collects less revenue as a result of the threshold falling, but raises more revenue as a result of the MLS rate increasing. PHI take-up rises, and thus the budgetary cost of the rebate rises as well.

\section{Figure 6: The effect of a reduction in the PHI rebate for incomes above a certain threshold}

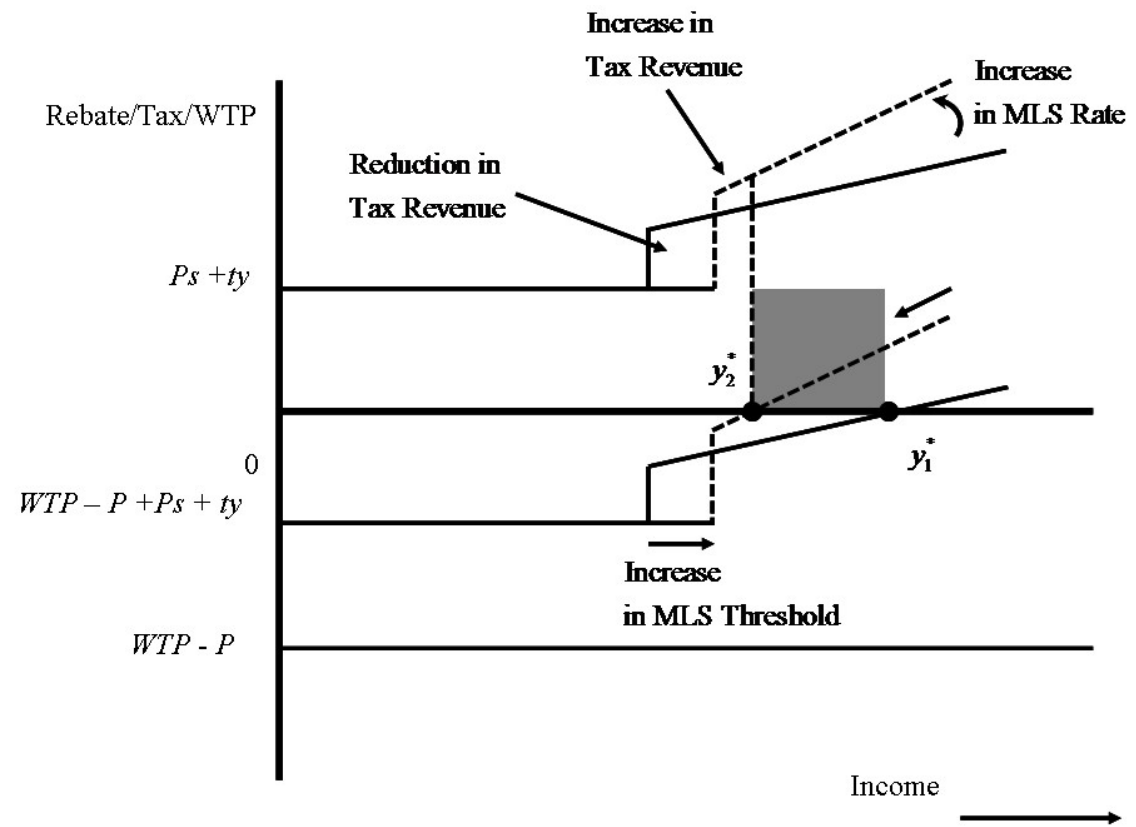

The effect of means testing the $\mathrm{PHI}$ rebate

Means testing the PHI rebate is also straightforward to analyse within this framework. To isolate the effects of this policy change, we examine the effect of establishing a threshold beyond which the PHI rebate is reduced.

The policy change either has no effect or reduces PHI take-up. The latter case is illustrated in Figure 7 below. The PHI rebate is reduced for individuals with income above the level indicated, and the reduction induces some individuals to drop their PHI cover. As a result, PHI take-up falls to $y_{2^{\prime}}{ }^{\prime}$ the budgetary cost of the PHI rebate falls, and MLS revenue increases. 
Figure 7: Means testing the $\mathrm{PHI}$ rebate reduces $\mathrm{PHI}$ take-up

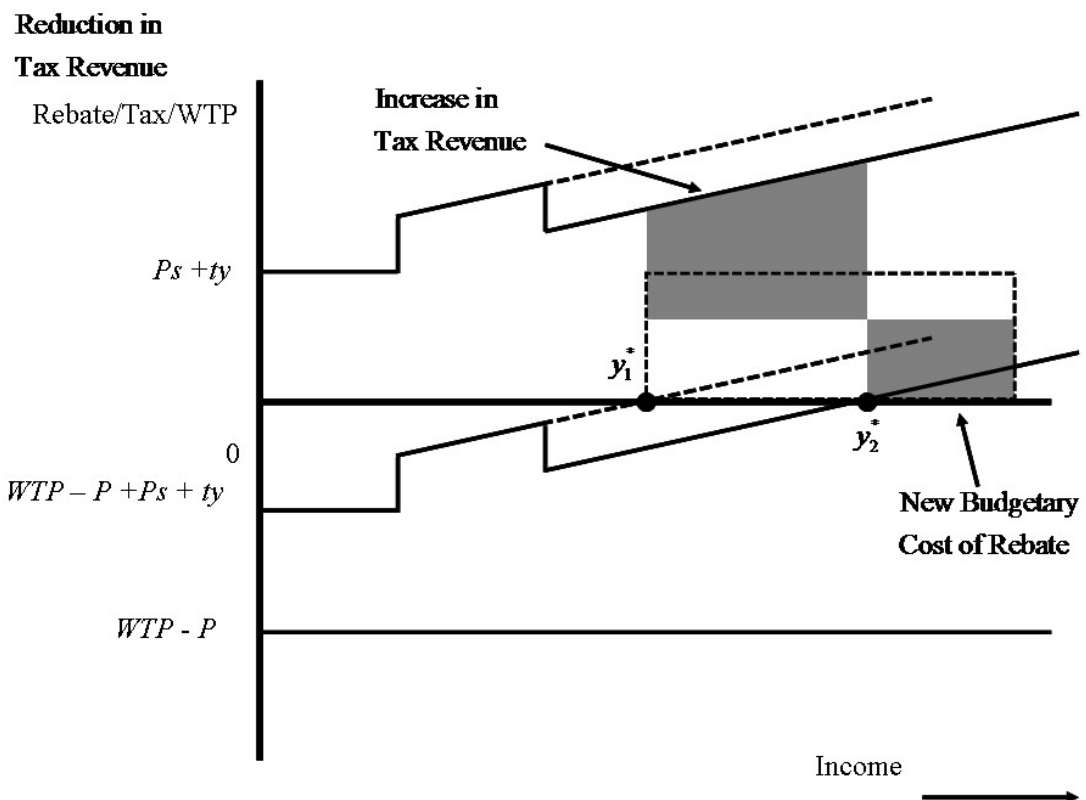

It is also straightforward to draw the diagram so that means testing the PHI rebate has no effect on PHI take-up. The reduction in Figure 7 may simply not be large enough to affect consumers who are already purchasing PHI. The only effect of such a policy change in these circumstances would be to reduce budgetary PHI rebate outlays.

\section{Discussion of results and broader consequences for private health insurance in Australia}

This paper has presented an analytical framework for examining changes in the PHI rebate and the Medicare Levy Surcharge. The analysis shows that there are many subtleties involved in assessing the effects of these policies on PHI take-up rates, tax revenues, and budgetary outlays.

Simultaneously increasing the MLS rate and threshold will have an ambiguous effect on PHI take-up rates, whilst means testing the PHI rebate cannot increase PHI take-up, and will reduce it in some circumstances. Ultimately, the actual effect on PHI take-up rates of policy changes (such as those that have been proposed by the Australian Government) is an empirical matter that cannot be settled by theory alone. 
Complicating all of this is the effect that existing and proposed policies have on underlying market parameters. One of the key unambiguous conclusions of this paper is the effect of policy instruments on market price elasticity of PHI demand. This elasticity falls as more individuals that are left in the PHI pool become MLS avoiders as a consequence of ever-higher MLS rates.

Depending on the degree of imperfect competition in the PHI market, the reduction in the overall price elasticity of demand may also provide an additional incentive for PHI providers to increase mark-ups (the excess of price above cost). To the extent that low-income consumers of PHI tend to be relatively more price elastic (and to the extent that PHI providers cannot price discriminate on the basis of income), this would result in higher premiums for those that remain in PHI, which could drive up PHI rebate outlays. It could also result in a second round of low-income consumers leaving PHI, with the initial effect on higher demands for public resources and waiting times exacerbated as the price of PHI rises.

A lower overall price elasticity of demand may also have less direct (but no less significant) implications for upstream firms in the health industry and for consumers of those services. Suppliers of inputs (such as specialists, diagnostic providers, and private hospitals) may themselves respond to lower PHI elasticities by increasing their own prices, in an attempt to 'capture' the additional rents that are created when consumers of a complementary good become less willing to change their behaviour in response to price increases. This increase in supplier costs would in turn have further negative implications for public outlays, particularly for specialist charges that are covered under the Medicare system. To the extent that public hospitals are budget-constrained and compete for the same input suppliers as private providers, there will be further rationing of these services in the public system, reducing the welfare of public patients.

These consequences point to greater pressure being placed on the public system and budgetary outlays. Note that, because of the effect of higher MLS rates on the price elasticity of demand for PHI, these indirect effects that we have discussed here could still occur, even if those MLS changes did not directly result in lower overall PHI demand. In other words, one of the unintended consequences of increasing MLS rates could be to drive up costs in the public system, but this effect is conceptually distinct from the usual mechanism through which public outlays would increase as a result of lower PHI take-up.

There may also be another set of consequences for suppliers and the pool of PHI consumers that continue to purchase PHI. To the extent that low willingness to pay reflects low risks, and to the extent to which low-income, low-willingnessto-pay consumers drop their PHI cover as MLS thresholds rise, the overall 
riskiness of the remaining pool of PHI consumers will increase, exacerbating adverse selection problems and driving up provider costs and pressure on premiums. The extent to which this would set off an 'adverse selection death spiral' in which a riskier pool of remaining consumers increases costs, drives up premiums, and results in further reductions in PHI demand depends on exactly how many low-risk consumers drop their PHI cover.

Even if adverse selection problems are not exacerbated, the reduction in overall PHI demand (for a given set of PHI prices) would mean that marginal PHI providers would be forced to exit the industry, reducing competitive pressure among suppliers and placing further upward pressure on PHI premiums. This would mean that annual regulatory decisions regarding PHI premium increases would take place in an environment of reduced competition and less switching between providers, as well as a lower overall price elasticity of demand.

\section{References}

Barrett, G. and Conlon, R. 2003, 'Adverse Selection and the Decline in Private Health Insurance Coverage in Australia: 1989-1995', Economic Record 79: 279-96.

Becker, G. and Ehrlich, I. 1972, 'Market Insurance, Self-insurance and SelfProtection', Journal of Political Economy 80(4): 623-48.

Biggs, A. 2009, 'Private health insurance premium increases - an overview', Background Note, Parliamentary Library, August.

Butler, J. 2002, 'Estimating Elasticities of Demand for Private Health Insurance in Australia', NCEPH Working Paper No. 43, Canberra.

Butler, J. 2002, 'Policy Change and Private Health Insurance: Did the Cheapest Policy do the Trick?' Australian Health Review 25(6): 33-41.

Cameron, C. and Trivedi, P. 1991, 'The Role of Income and Health Risk in the Choice of Health Insurance: Evidence from Australia', Journal of Public Economics 45: 1-28.

Cleeton, D. and Zellner, B. 1993, 'Income, Risk Aversion, and the Demand for Insurance', Southern Economic Journal 60: 146-56.

Commonwealth of Australia 2009, Report on the Fairer Private Health Insurance Incentives Bill 2009 and Two Related Bills, Senate Community Affairs Legislation Committee, August. 
Commonwealth Treasury 2000-2008, Tax Expenditure Statements, various issues.

Frech, T., Hopkins, S. and Macdonald, G. 2003, 'The Australian Health Insurance Boom: Was It Subsidies or Liberalised Regulation?' Economic Papers 22(1): $58-64$.

Hoy, M. and Robson, A. 1981, 'Insurance as a Giffen Good', Economics Letters 47-51.

Mossin, J. 1968, 'Aspects of Rational Insurance Purchasing', Journal of Political Economy 76(4): 553-68.

Palagkaraya, A. and Yong, J. 2005, 'Effects of Recent Carrot and Stick Policy Initiatives on Private Health Insurance Coverage in Australia', Economic Record 81: 262-72. 